\title{
Mature Teratoma Revealed by an Encysted Pleural Effusion
}

\author{
Houda Gharsalli1,2*, Monia Attia ${ }^{2,3}$, Sarra Zairi' ${ }^{2,4}$, Imen Sahnoun 1,2, Aida Ayadi ${ }^{2,5}$, Henda Neji ${ }^{2,3}$, \\ Sonia Maalej1,2, Leila Douik ElGharbi1,2
}

${ }^{1}$ Department of Pulmonology, Abderrahmane Mami Hospital, Ariana, Tunisia

${ }^{2}$ University of Tunis El Manar, Tunis, Tunisia

${ }^{3}$ Department of Radiology, Abderrahmane Mami Hospital, Ariana, Tunisia

${ }^{4}$ Department of Thoracic and Cardiovascular Surgery, Abderrahmane Mami Hospital, Ariana, Tunisia

${ }^{5}$ Department of Pathology, Abderrahmane Mami Hospital, Ariana, Tunisia

Email: *houdagharsalli@yahoo.fr

How to cite this paper: Gharsalli, H., Attia, M., Zairi, S., Sahnoun, I., Ayadi, A., Neji, H., Maalej, S. and ElGharbi, L.D. (2021) Mature Teratoma Revealed by an Encysted Pleural Effusion. Open Journal of Respiratory Diseases, 11, 84-89.

https://doi.org/10.4236/ojrd.2021.112008

Received: March 7, 2021

Accepted: May 25, 2021

Published: May 28, 2021

Copyright (c) 2021 by author(s) and Scientific Research Publishing Inc. This work is licensed under the Creative Commons Attribution International License (CC BY 4.0).

http://creativecommons.org/licenses/by/4.0/

\begin{abstract}
A 32-year-old patient with no previous history was admitted for chest pain, dyspnea, appetite and weight loss. Chest X-ray revealed an opacity involving the lower two-thirds of the right hemithorax, suggestive of a pleural effusion. Because of the absence of fluid return even after ultrasound-guided thoracentesis, a Chest Computed tomography was required showing a heterogeneous anterior mediastinal mass with soft tissue, fat, fluid and calcifications associated with extensive encysted fluid collection in the right hemithorax. A video-assisted mini-thoracotomy revealed a mediastinal tumor firmly attached to the thymus with a cystic wall lined by squamous epithelium and sebaceous gland composed of respiratory tissue, adipose tissue, cartilage, smooth muscle fibers, and well-differentiated pancreatic tissue. These findings led to the diagnosis of a mature thymic teratoma. The patient was discharged 7 days after surgery, with no recurrence on follow-up.
\end{abstract}

\section{Keywords}

Tumor of the Mediastinum, Mature Teratoma, Pleural Effusion

\section{Introduction}

Mediastinal teratoma is the most common mediastinal germ cell tumor [1]. It is traditionally found in the in anterior mediastinum and occurs in the age of 20 40 years [1]. Mediastinal teratoma is composed of tissues derived from the endoderm, mesoderm and ectoderm and according to the degree of differentiation, it can be divided into mature and immature teratoma [1] [2]. Mature mediastinal 
teratomas are infrequent, slow-growing, and often found incidentally [3]. Symptoms are often a result of compression or obstruction of surrounding organ including mainly chest discomfort, dyspnea, cough, dysphagia [4] Symptoms related to digestive enzymes secretion within the tumor with devastating effects on the bronchi, lung, pericardium or pleura [4] should be considered as possible signs which can reveal the mediastinal tumor.

\section{Patient and Observation}

A 32-year-old non-smoker man, without comorbidities neither medication history presented for a two-week history of right chest pain, fever and dyspnea. The patient reported lack of appetite for the last 2 months, with a 3-kg weight loss. He didn't have any risk factors for the human immunodeficiency virus (HIV), or tuberculosis (TB) contact and didn't complain from night sweats or cough. His vital signs were within normal limits with temperature of 37.2 , a pulse rate of 85 beats/min and blood pressure of 130/70 $\mathrm{mmHg}$. The chest examination revealed a respiratory rate of 20 breaths/min and decreased vocal resonance with absence of breath sounds at the lower right hemithorax. There were no peripheral palpable lymph nodes. Pulse oximetry was $98 \%$ in room air.

Chest X-Ray (Figure 1) showed a homogenous opacity involving right hemithorax, suggesting a pleural effusion. An emergent thoracentesis was attempted in order to rule out an empyema, but was unsuccessful. An ultrasound examination was done revealing an encysted pleural effusion with pleural thickening (Figure 2). A second attempt for thoracentesis with ultrasound guidance was also unsuccessful. Chest Computed tomography (CT) showed a large heterogenous right-sided anterior mediastinal mass measuring $55 \mathrm{~mm}$ with cystic, tissue and fatty components. Calcifications were also found in tumour's lower part. A homolateral encysted pleural effusion was associated (Figure 3). There was no communication between this mass and the pleural compartment. The diagnosis

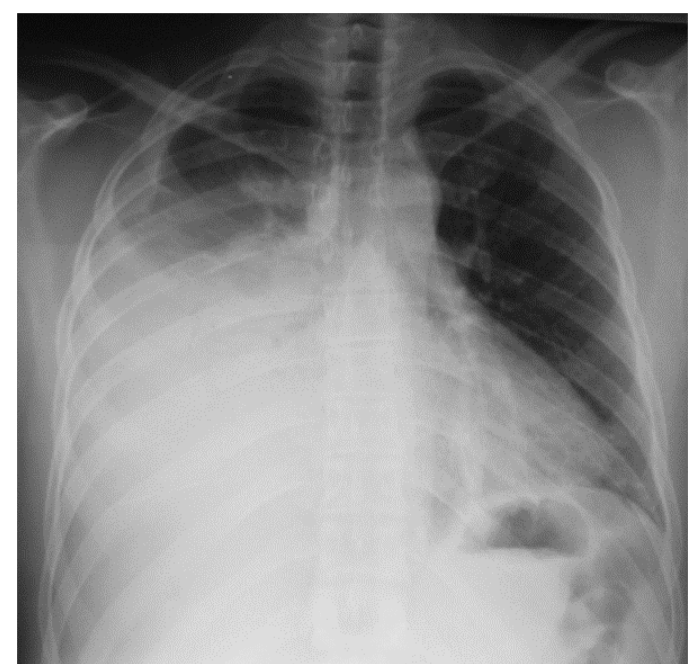

Figure 1. Homogeneous opacity involving the middle and the lower zone of the right hemithorax. 

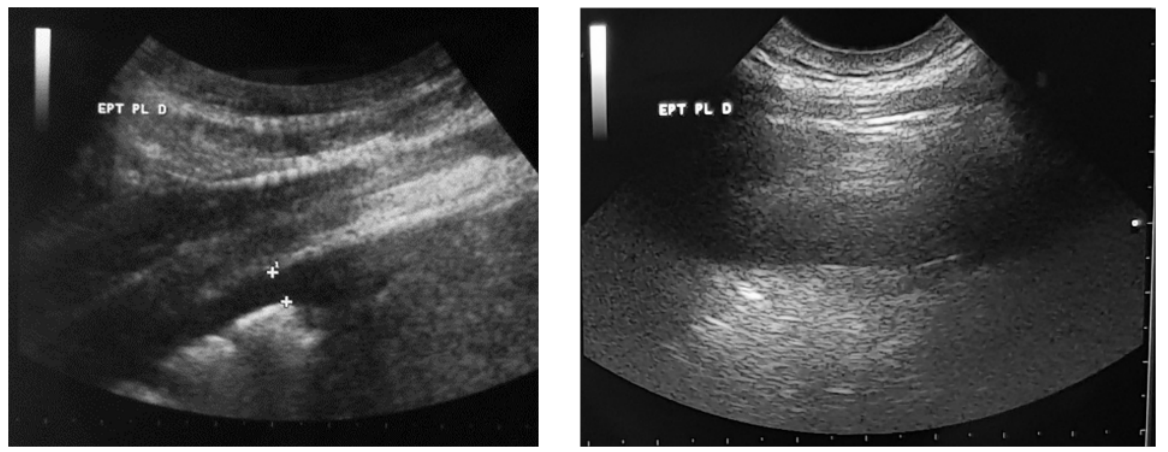

Figure 2. Ultrasound exam: encysted pleural effusion with pleural thickening.

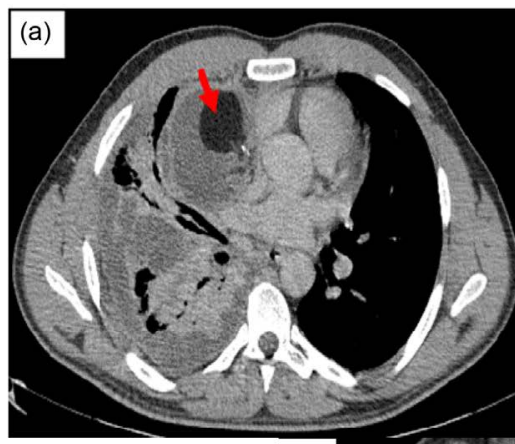

(b)

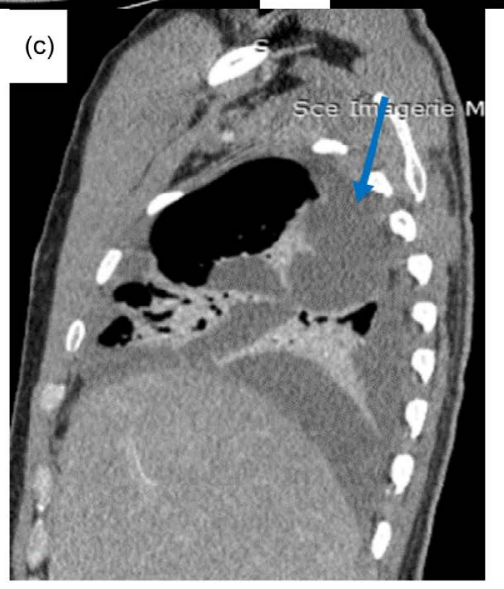

Figure 3. (a): Enhanced thoracic computed tomography: axial view: Heterogenous mediastinal anterior mass including cystic, tissue and fatty components (red arrows). (b): Calcifications were also noted in the lower extremity (yellow arrow). (c): Sagittal view: a right-sided multil-encysted pleural effusion (blue arrow).

of an anterior mediastinal teratoma associated with a right sided pleural effusion was evoked. In order to ascertain the diagnosis and rule out other mediastinal malignancies, alpha-fetoprotein and serum beta human chorionic gonadotropin were performed and were within normal limits. Surgery was decided through a video-assisted thoracoscopic approach. At exploration, the pleura was thickened. Pleural debridement was performed and 1 litter of pleural fluid was evacuated. The tumour was firmly attached to the thymus. There were no communication between the tumour's content and the pleural cavity. Complete resection of the large anterior mediastinal mass was performed. Pathologic examination showed 
a cystic component lined by a squamous epithelium. In addition, sebaceous glands, cartilage, smooth muscle fibers, fatty, pulmonary and well-differentiated pancreatic tissues were also identified (Figure 4, Figure 5). Residual thymic tissue was noticed in lesion's peripheral part. There wasn't any morphological evidence of malignancy. Diagnosis of mature thymic teratoma was finally established. The postoperative course was uneventful. The patient was discharged 7 days after surgery. Six months postsurgery patient had no significant complaints with radiological improvement.

\section{Discussion}

This case highlights that mature mediastinal teratomas can have atypical presentation and can be revealed by encysted pleural effusion. These tumors are

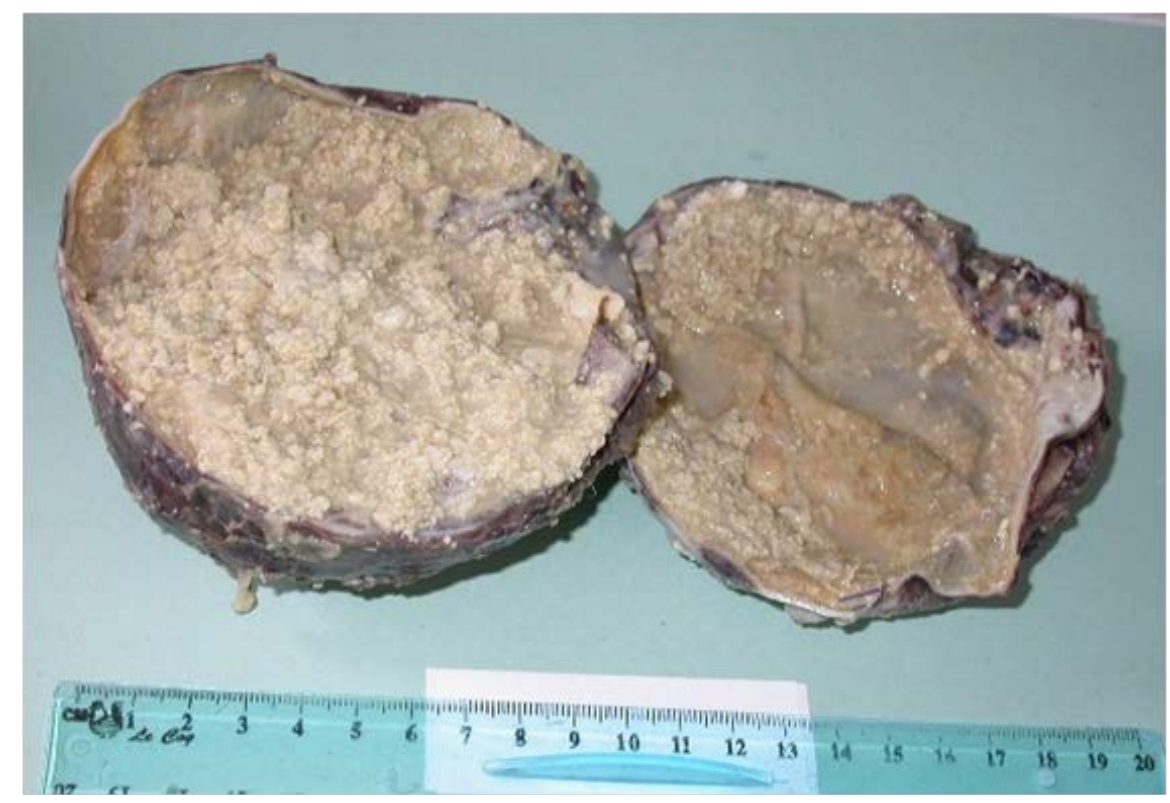

Figure 4. Eight $\mathrm{cm}$ well-limited cystic tumour, with a thickened white wall and mammelonated internal surface (lumpy material and hair).

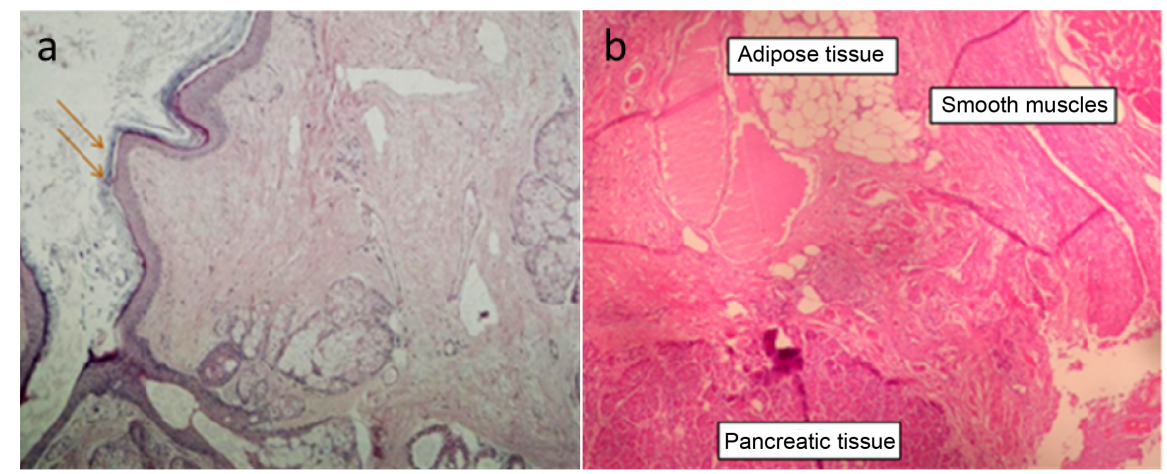

Figure 5. (a): $(\mathrm{HE} \times 40)$ : Cystic wall lined with a squamous epithelium, associated with sebaceous glands, $(\mathrm{b})$ : $(\mathrm{HE} \times 40)$ : Respiratory tissue, adipose tissue, cartilage, smooth muscle fibers, well-differentiated pancreatic tissue. Peripheral part of the lesion: residual thymic tissue. 
asymptomatic in most cases. However, they may be revealed by dyspnea (25\%), thoracic pain (23\%) or cough (17\%) [5] [6]. Pleural effusion was rarely reported in such cases [7]. For our patient, a 32-year-old non-smoker man, with an encysted pleural effusion, diagnoses of pneumonia, tuberculosis and cancer were discussed. Thoracic computed tomography showed typical patterns of mediastinal teratoma, with tissue, fluid, fat and calcium densities [8]. Microscopically, mature teratomas are often made of well-differentiated ectodermal (skin, hair, sweat glands and tooth), mesodermal (fat, cartilage, bone and smooth muscle) as well as endodermal (respiratory and intestinal epithelium) elements in varying proportions [9] [10]. In our case, in addition to these usual tissues, the tumour contained pancreatic tissue which was rarely reported in mediastinal mature teratoma [5]. No communication between the tumour and pleural cavity was observed. Pleural effusion could be explained either by pleural inflammatory reactionin contact with the teratoma [11] or probably by diffusion of proteolytic enzymes secreted by pancreatic tissue. This hypothesis was reported by Beduneau et al. [12]. Surgical removal of teratoma is essential because of pleural or pericardial risk of rupture or malignant transformation [11] [13].

\section{Conclusion}

We presented this case to illustrate an atypical presentation of mature mediastinal teratoma. Pulmonologist should think of mediastinal teratoma as a possible etiology for an encysted pleural effusion of unknown origin, especially in young adults.

\section{Competing Interests}

The authors declare no competing interest.

\section{Authors' Contributions}

All authors contributed to this work. They also read and approved the final version of this work.

\section{References}

[1] Tian, Z.H., Liu, H.S., Li, S.Q., Chen, Y.Y., Ma, D.J., Han, Z.J., et al. (2020) Surgical Treatment of Benign Mediastinal Teratoma: Summary of Experience of 108 Cases. Journal of Cardiothoracic Surgery, 15, Article No. 36. https://doi.org/10.1186/s13019-020-1075-8

[2] Dulmet, E.M., Macchiarini, P., Suc, B. and Verley, J.M. (1993) Germ Cell Tumors of the Mediastinum. A 30-Year Experience. Cancer, 72, 1894-1901. https://doi.org/10.1002/1097-0142(19930915)72:6<1894::AID-CNCR2820720617>3. 0.CO;2-6

[3] Ryan, E., Shennib, H. and Gopal, S.J. (2019) Giant Intrathoracic Teratoma Presenting with Cachexia and Severe Dyspnea. Journal of Cardiothoracic Surgery, 14, Article No. 96. https://doi.org/10.1186/s13019-019-0922-y

[4] Duwe, B.V., Sterman, D.H. and Musani, A.I. (2005) Tumors of the Mediasinum. 
Chest, 128, 2893-2909. https://doi.org/10.1378/chest.128.4.2893

[5] Agrawal, T., Blau, A.J., Chwals, W.J. and Tischler, A.S. (2016) A Unique Case of Mediastinal Teratoma with Mature Pancreatic Tissue, Nesidioblastosis, and Aberrant Islet Differentiation: A Case Report and Literature Review. Endocrine Pathology, 27, 21-24. https://doi.org/10.1007/s12022-015-9393-4

[6] Mohd, E.N., Mohd, R.A., Bakar, N.S., Mohd, K.M., Ismail, A.I. and Abdul, R.M. (2016) Cystic Teratoma Mimicking Recurrent Pleural Effusion, Complicated by Mycobacterium Abscessus Infection. Respirology Case Reports, 4, e00155. https://doi.org/10.1002/rcr2.155

[7] Razi, E., Imani, A., Ansari, I., Khamechian, T. and Davoodabadi, A. (2017) Pleural Effusion as a Rare Manifestation of Mediastinal Teratoma: A Case Report. Respiratory Medicine Case Reports, 22, 142-144. https://doi.org/10.1016/j.rmcr.2017.07.012

[8] Takahashi, K. and Al-Janabi, N.J. (2010) Computed Tomography and Magnetic Resonance Imaging of Mediastinal Tumors. Journal of Magnetic Resonance Imaging, 32, 1325-1339. https://doi.org/10.1002/jmri.22377

[9] Dhond, A.P., Agrawal, S.O., Sirmukaddam, S.V., Srinath, S., Roplekar, P. and Desai, P.R. (2016) Mediastinal teratoma: A Case Report with Review of Literature. Journal of the Scientific Society, 43, 57-59. https://doi.org/10.4103/0974-5009.175469

[10] Yasa, K.P., Permana, A.A.C.T. and Dewi, S.M. (2020) Mediastinal Benign Mature Teratoma in Young Girl, Catastrophic Delayed and Complications of Surgery: A Case Report. Open Access Macedonian Journal of Medical Sciences, 8, 201-204. https://doi.org/10.3889/oamjms.2020.3363

[11] Abid, H., Neji, H., Haddar, S., Ammar, I., Ayadi, L., Msaad, S., et al. (2013) Mediastinal Mature Teratoma with Spontaneous Malignant Transformation. Revue des Maladies Respiratoires, 30, 424-428. https://doi.org/10.1016/j.rmr.2012.11.006

[12] Beduneau, G., Cuvelier, A., Héliot, P., Métayer, J. and Muir, J.F. (2002) Mediastinal Teratoma with Recurrent Encysted Pleural Effusion. Revue des Maladies Respiratoires, 19, 367-370.

[13] No, T.H., Seol, S.H., Seo, G.W., Kim, D.I., Yang, S.Y., Jeong, C.H., et al. (2015) Benign Mature Teratoma in Anterior Mediastinum. Journal of Clinical Medicine Research, 7, 726-728. https://doi.org/10.14740/jocmr2270w 